\title{
Long non-coding RNA BACE1-AS is a novel target for anisomycin-mediated suppression of ovarian cancer stem cell proliferation and invasion
}

\author{
QING CHEN ${ }^{1}$, XINGHUI LIU ${ }^{1}$, LIMIN XU $^{1}$, YING WANG $^{1}$, SUWEI WANG $^{2}$, \\ QIONG $\mathrm{LI}^{2}$, YONGYI HUANG ${ }^{3,4}$ and TE LIU ${ }^{2,3}$
}

\begin{abstract}
${ }^{1}$ Gongli Hospital Affiliated to The Second Military Medical University in Pudong New Area of Shanghai City, Shanghai 200135; ${ }^{2}$ Shanghai Geriatric Institute of Chinese Medicine, Longhua Hospital, Shanghai University of Traditional Chinese Medicine, Shanghai 200031; ${ }^{3}$ Shanghai Tenth People's Hospital, Tongji University, Shanghai 200072, P.R. China; ${ }^{4}$ Laboratoire PROTEE, Bâtiment R, Université du Sud Toulon-Var, F-83957 La Garde Cedex, France
\end{abstract}

Received November 2, 2015; Accepted December 16, 2015

DOI: $10.3892 /$ or.2016.4571

\begin{abstract}
Human ovarian cancer stem cells (OCSCs) are one of the main factors affecting ovarian cancer cell metastasis, recurrence, prognosis and tolerance to chemotherapy drugs. However, the mechanisms of OCSC proliferation and invasion are not clear. Recent studies suggest that anisomycin can inhibit the proliferative and invasive ability of various tumor cells by increasing the production of the toxic amyloid $\beta$ (A $\beta 1-42)$ peptides from the amyloid precursor protein (APP). We explored whether anisomycin could also suppress human OCSC proliferation and invasion. The $\mathrm{CD} 44^{+} / \mathrm{CD} 117^{+}$OCSCs were enriched from human clinical ovarian tumor tissues. OCSCs treated with anisomycin showed reduced proliferation compared to controls. Moreover, anisomycin significantly suppressed the invasive capacity of OCSCs in vitro, as indicated by cell migration assays. The mRNA expression levels of long non-coding RNA (lncRNA) $\beta$-site APP cleaving enzyme 1 antisense strand (BACE1-AS) were significantly increased in anisomycin-treated OCSCs compared to controls. In addition, mRNA and protein levels of BACE1 and A $\beta 1-42$ were increased in anisomycin-treated OCSCs compared to controls. We confirmed that anisomycin suppressed the growth of xenograft tumors formed by OCSCs in vivo. Finally, when expression of lncRNA BACE1-AS was silenced using siRNA, BACE1 expression was downregulated and the antiproliferative and anti-invasive effects of anisomycin were reduced. Overall, we identified lncRNA BACE1-AS as a novel target for
\end{abstract}

Correspondence to: Professor Te Liu, Shanghai Tenth People's Hospital, Tongji University, 301 Yanchang Road, Shanghai 200072, P.R. China

E-mail: teliu79@126.com

Key words: ovarian cancer stem cells, anisomycin, long non-coding RNA BACE1-AS anisomycin. Elevation of lncRNA BACE1-AS expression is a potential mechanism for suppressing human OCSC proliferation and invasion.

\section{Introduction}

Human ovarian cancer stem cells (OCSCs) are one of the main factors affecting ovarian cancer metastasis, recurrence, prognosis and tolerance to chemotherapy drugs (1-9). To date, there are no effective therapies to inhibit OCSC proliferation or invasion. While the mechanisms of OCSC proliferation and invasion remain unclear, recent studies suggest that proteins involved in Alzheimer's disease etiology, including the amyloid precursor protein (APP) and amyloid $\beta(\mathrm{A} \beta)$ peptides, may be involved $(10,11)$.

A recent study showed that inhibition of microRNA-20a expression increases APP expression and suppresses ovarian cancer cell proliferation and invasion (10). Similarly, other studies indicate that anisomycin, a small molecule antibiotic, can inhibit the proliferative and invasive ability of some tumor cells by increasing the production of the toxic amyloid $\beta$ (A $\beta 1-42)$ peptides from APP $(11,15-19)$. In particular, anisomycin [2-(p-methoxybenzyl)-3,4-pyrrolidinediol-3-acetate] increases mRNA expression of APP, $\beta$-site APP cleaving enzyme 1 (BACE1 or $\beta$-secretase) and presenilin 1 (PS1) in a human SH-SY5Y cell line (10). In turn, APP influences cell adhesion, motility and proliferation, and is renowned for its ability to produce toxic A $\beta 1-42$ peptides (11). Toxic A $\beta 1-42$ peptides are generated from the cleavage of APP by BACE1 and the $\gamma$-secretase complex (which consists of PS1) (10). In neuronal cells, $A \beta 1-42$ destroys the integrity of the cell membrane (10-14). However, few studies have investigated the effects of APP and A $\beta 1-42$ on tumor cell proliferation, invasion and tumorigenesis.

Another important factor regulating $A \beta 1-42$ production is the expression of the long non-coding RNA BACE1-antisense transcript (lncRNA BACE1-AS), which is upregulated in patients with Alzheimer's disease. The lncRNA can stabilize 
BACE1 mRNA and generate additional BACE1 through a feed-forward mechanism, thereby stimulating A $\beta 1-42$ production $(12,13)$. However, whether IncRNA BASE1-AS increases A $\beta 1-42$ production in tumor cells treated with anisomycin remains unknown.

While anisomycin has been shown to have antiproliferative ability in Jurkat T cells (16) and enhance apoptosis of various cancer cell types [including renal carcinoma, glucocorticoid resistant acute lymphoblastic leukemia and glioma cells (15)], the effects of anisomycin on human OCSCs are not well studied. We hypothesized that anisomycin could suppress human OCSC proliferation and invasion by stimulating lncRNA BACE1-AS and upregulating A $\beta 1-42$ expression. Using ovarian cancer stem cells derived from seven ovarian cancer patients, we analyzed the expression levels of lncRNA BACE1-AS, APP, A $\beta 1-42$ and apoptosis-related proteins after treatment with anisomycin. We also investigated whether silencing of lncRNA BACE-1 expression using siRNA would alter the anisomycin-related antiproliferative and anti-invasive effects.

\section{Materials and methods}

Isolation of $\mathrm{CD} 44^{+} / \mathrm{CD} 117^{+}$ovarian cancer stem cells. All samples were collected from the inpatient clinic of Shanghai Pudong New Area Gongli Hospital (Shanghai, China) between June 2013 and December 2014. All human materials were obtained according to consent regulation and approved by the Ethics Review Committee of the World Health Organization of Collaborating Center of Research in Human Production authorized by Shanghai Municipal Government. Briefly, $4 \mu \mathrm{l}$ of $\mathrm{CD}_{4} 4^{+}$and $\mathrm{CD} 117^{+}$primary monoclonal antibodies (mouse anti-human CD117-FITC, rabbit anti-human CD44-PE; eBioscience) at $1 \mathrm{mg} / 100 \mathrm{ml}$ were added to the primary ovarian cancer cell sediment to block nonspecific binding, and the cells were stored at $4^{\circ} \mathrm{C}$ in phosphate-buffered saline (PBS) for $30 \mathrm{~min}$ in a volume of $1 \mathrm{ml}$ as previously described $(1,3,4,9)$. After the reaction, the cells were washed twice in PBS. They were isolated and enriched by flow cytometry (BD FACSAria; BD Biosciences, San Jose, CA, USA), incubated at $10^{\circ} \mathrm{C}$ in PBS for $15 \mathrm{~min}$ before being washed twice in PBS. Single cells were plated at 1,000 cells $/ \mathrm{ml}$ in Dulbecco's modified Eagle's medium (DMEM):F12 (HyClone), supplemented with $10 \mathrm{ng} / \mathrm{ml}$ basic fibroblast growth factor (bFGF), $10 \mathrm{ng} / \mathrm{ml}$ epidermal growth factor (EGF), $5 \mu \mathrm{g} / \mathrm{ml}$ insulin and $0.5 \%$ bovine serum albumin (BSA) (all from Sigma-Aldrich). All CD $44^{+} / \mathrm{CD} 117^{+}$cells were cultured in the above conditions as non-adherent spherical clusters, termed ovarian carcinoma-initiating cells. All cells were cultured under the same conditions until passage three, when they were used for further experiments.

RNA extraction and analysis by quantitative real-time $P C R$ ( $q R T-P C R)$. Total RNA from each cell was isolated using TRIzol reagent (Invitrogen), according to the manufacturer's protocol. The RNA samples were treated with DNase I (Sigma-Aldrich, St. Louis, MO, USA), quantified and reverse-transcribed into cDNA using the ReverTra Ace- $\alpha$ First Strand cDNA Synthesis kit (Toyobo). Quantitative RT-PCR was conducted using a RealPlex4 real-time PCR detection system from Eppendorf Co., Ltd. (Germany), with
SYBR-Green Real-Time PCR Master Mix (Toyobo) as the detection dye. Amplification was performed over 40 cycles with denaturation at $95^{\circ} \mathrm{C}$ for $15 \mathrm{sec}$ and annealing at $58^{\circ} \mathrm{C}$ for $45 \mathrm{sec}$. Target cDNA was quantified using the relative quantification method. A comparative threshold cycle $(\mathrm{Ct})$ was used to determine gene expression relative to a control (calibrator) and steady-state mRNA levels are reported as an $\mathrm{n}$-fold difference relative to the calibrator. For each sample, the maker gene $\mathrm{Ct}$ value was normalized using the formula $\mathrm{Ct}=\mathrm{Ct}$ _genes-Ct_18sRNA. To determine relative expression levels, the following formula was used: $\Delta \Delta \mathrm{Ct}=\Delta \mathrm{Ct}$ all_ groups- $\Delta \mathrm{Ct}$ tblank control_group. The values used to plot relative expression of markers was calculated using the expression $2^{-\Delta \Delta \mathrm{Ct}}$. The mRNA levels were calibrated based on levels of 18s rRNA. The cDNA of each gene was amplified using primers as previously described $(12,13)$.

Northern blot analysis. Northern blotting experiments were performed as previously described $(7,13)$. For all samples, $20 \mu \mathrm{g}$ of good quality total RNA was analyzed on a $7.5 \mathrm{M}$ urea $12 \%$ polyacrylamide denaturing gel and transferred to a Hybond $\mathrm{N}^{+}$nylon membrane (Amersham, Freiburg, Germany). Membranes were cross-linked using UV light for $30 \mathrm{sec}$ at $1,200 \mathrm{~mJ} / \mathrm{cm}^{2}$. Hybridization was performed with the antisense starfire probe to be detected the lncRNA BACE1-AS fragments according to the manufacturer's instructions $(12,13)$. After washing, membranes were exposed for 20-40 h to Kodak XAR-5 film (Sigma-Aldrich). As a positive control, all membranes were hybridized with a human U6 snRNA probe, 5'-GCAGGGGCCATGCTAATCTTCTCTGTAT CG-3'. Exposure times for the U6 control probe varied between 15 and $30 \mathrm{~min}$.

Methylthiazolyl tetrazolium (MTT) assay for cell proliferation. Cells were seeded $\left(2 \times 10^{3} /\right.$ well) in 96 -well plates and cultured in DMEM supplemented with $10 \%$ fetal bovine serum (FBS) at $37^{\circ} \mathrm{C}$ with $5 \% \mathrm{CO}_{2}$, until $85 \%$ confluent. 3-(4,5-Dimethylthiazol-2-yl)-2,5-diphenyltetrazolium bromide (MTT); Sigma Chemicals reagent $(5 \mathrm{mg} / \mathrm{ml})$ was added to the maintenance cell medium at different time points, and incubated at $37^{\circ} \mathrm{C}$ for an additional $4 \mathrm{~h}$. The reaction was terminated with the addition of $150 \mu 1$ dimethylsulfoxide (DMSO; Sigma Chemicals) per well. Cells were lysed for $15 \mathrm{~min}$, and the plates were gently shaken for $5 \mathrm{~min}$. Absorbance values were determined using the enzyme-linked immunosorbent assay (ELISA) reader (Model 680; Bio-Rad) at $490 \mathrm{~nm}$.

Western blot analysis. Total protein extracts were resolved by $12 \%$ SDS-PAGE and transferred on polyvinylidene difluoride (PVDF) membranes (Millipore). After blocking, the PVDF membranes were washed four times for $15 \mathrm{~min}$ with Trisbuffered saline with Tween-20 (TBST) at room temperature and incubated with primary antibody (Table I). Following extensive washing, membranes were incubated with secondary peroxidase-linked goat anti-rabbit IgG (1:1,000; Santa Cruz Biotechnology) for $1 \mathrm{~h}$. After washing four times for $15 \mathrm{~min}$ with TBST at room temperature, the immunoreactivity was visualized by enhanced chemiluminescence (ECL kit; Pierce Biotechnology), and membranes were exposed to Kodak XAR-5 film. 
Table I. The source and dilutions of primary antibodies.

\begin{tabular}{|c|c|c|}
\hline Antibodies & Companies & Applications \\
\hline Rabbit anti-human $A \beta 1-42$ & Cell Signaling Technology, Danvers, MA, USA & $\begin{array}{l}\text { WB }(1: 1,000) \\
\text { ICH }(1: 100)\end{array}$ \\
\hline Goat anti-human BACE1 & Santa Cruz Biotechnology, Santa Cruz, CA, USA & $\begin{array}{l}\text { WB }(1: 1,000) \\
\text { ICH }(1: 100)\end{array}$ \\
\hline Rabbit anti-human Ki67 & Santa Cruz Biotechnology, Santa Cruz, CA, USA & $\begin{array}{l}\text { WB }(1: 1,000) \\
\text { ICH }(1: 100)\end{array}$ \\
\hline Rabbit anti-human GAPDH & Cell Signaling Technology, Danvers, MA, USA & WB $(1: 1,000)$ \\
\hline Donkey anti-goat-Cy3 & Santa Cruz Biotechnology, Santa Cruz, CA, USA & IF $(1: 100)$ \\
\hline Goat anti-rabbit-FITC & Santa Cruz Biotechnology, Santa Cruz, CA, USA & IF $(1: 100)$ \\
\hline
\end{tabular}

Soft agar colony formation assay. All steps were performed as previously described in 6-well plates (7). The base layer of each well consisted of $2 \mathrm{ml}$ with final concentrations of $1 \mathrm{X}$ media (DMEM+10\% FBS) and $0.6 \%$ low melting point agarose. Plates were chilled at $4^{\circ} \mathrm{C}$ until solid and then a $1 \mathrm{ml}$ growth layer of agar was poured, consisting of $1 \times 10^{4}$ cells suspended in $1 \mathrm{X}$ media and $0.3 \%$ low melting point agarose. Plates were again chilled at $4^{\circ} \mathrm{C}$ until the growth layer congealed. An additional $1 \mathrm{ml}$ of $1 \mathrm{X}$ media without agarose was added on top of the growth layer on day 0 and again on day 15 of growth. Cells were allowed to grow at $37^{\circ} \mathrm{C}$ for 1 month and then the total number of colonies was counted. Assays were repeated three times. Results were statistically analyzed by paired t-test using the GraphPad Prism program.

Transwell migration assay. All steps were performed as previously described (1). Briefly, cells $\left(2 \times 10^{5}\right)$ were resuspended in $200 \mu \mathrm{l}$ of serum-free medium and seeded on the top chamber of the $8.0-\mu \mathrm{m}$ pore, $6.5 \mathrm{~mm}$ polycarbonate Transwell filters (Corning). A total of $600 \mu \mathrm{l}$ of DMEM+10\% FBS was added to the bottom chamber. The cells were allowed to migrate for $24 \mathrm{~h}$ at $37^{\circ} \mathrm{C}$ in a humidified incubator with $5 \% \mathrm{CO}_{2}$. The cells attached to the lower surface of the membrane were fixed in $4 \%$ paraformaldehyde at room temperature for $30 \mathrm{~min}$ and stained with 4,6-diamidino-2-phenylindole (DAPI) (C1002; Beyotime Institute of Biotechnology, China). The number of cells on the lower surface of the filters was counted under the microscope. A total of five fields were counted for each Transwell filter.

Annexin V-FITC/PI staining and flow cytometric analysis. Apoptosis was evaluated using an Annexin V-FITC/PI staining kit (Beyotime Institute of Biotechnology) according to the manufacturer's instructions and as previously described (16). Briefly, cells were seeded (3x10 $/$ well) in 6-well plates and cultured until $85 \%$ confluent. Cells were washed with PBS three times, and collected by centrifugation (Allegra $\mathrm{X}-22 \mathrm{R}$; Beckman Coulter) at $1,000 \mathrm{x} \mathrm{g}$ for $5 \mathrm{~min}$. The cell pellets were resuspended in $0.1 \mathrm{ml}$ of $\mathrm{PBS}$, stained with the Annexin V-FITC/PI kit, incubated for $30 \mathrm{~min}$ at $4^{\circ} \mathrm{C}$ and analyzed using a fluorescence-activated cell sorting (FACS) machine (BD FACSAria). A total of 20,000 events were acquired for analysis using CellQuest software.
Immunofluorescence (IF) staining. The cultured cells were washed three times with PBS and fixed with $4 \%$ paraformaldehyde (Sigma-Aldrich) for $30 \mathrm{~min}$. After blocking, the cells were incubated first with primary antibody (Table I) overnight at $4^{\circ} \mathrm{C}$, and then with FITC-conjugated goat anti-rabbit IgG antibody (1:200; Abcam, Cambridge, UK) and $5 \mu \mathrm{g} / \mathrm{ml}$ DAPI (Sigma-Aldrich) at room temperature for $30 \mathrm{~min}$. Cells were thoroughly washed with TBST and viewed through a fluorescence microscope (DMI3000; Leica, Allendale, NJ, USA).

In vivo xenograft experiments. OCSCs were divided into two groups: a negative control group (OCSCs pretreated with DMSO), which were treated with DMSO for $72 \mathrm{~h}$; and an experimental group (OCSCs pretreated with anisomycin), which were treated with anisomycin (at its half maximal inhibitory concentration, $\mathrm{IC}_{50}=8.5 \mu \mathrm{mol}$ ) for $72 \mathrm{~h}$. Approximately $1 \times 10^{5}$ logarithmically growing OCSCs were inoculated in BALB/c nude, or nude mice. Each experimental group consisted of seven mice. After seven weeks of observation, the mice were sacrificed and tumors were stripped $(7,8)$. Tumor weight was measured and tumor volume was calculated according to the formula: Tumor volume $\left(\mathrm{mm}^{3}\right)=\left(\mathrm{ab}^{2}\right) / 2$, where a, represents the longest axis (mm) and b, the shortest axis (mm).

Statistical analysis. Each experiment was performed as least three times and data are shown as the mean \pm SE where applicable. Differences were evaluated using Mann-Whitney test. The probability $\mathrm{p}<0.05$ was considered to indicate a statistically significant result.

\section{Results}

Patient population filter. We examined a total of seven ovarian cancer patients with undifferentiated and mixed epithelial ovarian carcinoma. The characteristics of all ovarian patients are summarized in Table II. The age, stage, grade of differentiation and histology distribution of the patient populations were released by the International Federation of Gynaecology and Obstetrics (FIGO) annual report for European countries $(1,7)$.

Anisomycin suppresses OCSC proliferation and invasion. Cell viability (MTT) assays revealed no significant difference in the viability of anisomycin $(8.5 \mu \mathrm{mol})$ treated OCSCs 
Table II. Characteristics of the patients cohort.

\begin{tabular}{|c|c|}
\hline Characteristics & Patients $(n=7)$ \\
\hline Age median (range) & $38-62$ \\
\hline$\leq 40$ & 2 \\
\hline $40-60$ & 4 \\
\hline$\geq 60$ & 1 \\
\hline \multicolumn{2}{|l|}{ Surgical staging } \\
\hline I a-c & 1 \\
\hline II a-c & 3 \\
\hline III a-c & 3 \\
\hline IV & - \\
\hline \multicolumn{2}{|l|}{ Histopathology } \\
\hline Serous & - \\
\hline Endometrioid & - \\
\hline Mucinous & - \\
\hline Clear cells & - \\
\hline $\begin{array}{l}\text { Others } \\
\text { (mixed epithelial, undifferentiated) }\end{array}$ & 7 \\
\hline \multicolumn{2}{|l|}{ Tumor grade } \\
\hline 1 & 1 \\
\hline 2 & 4 \\
\hline 3 or clear cell & 2 \\
\hline Unknown & - \\
\hline \multicolumn{2}{|l|}{ Treatments } \\
\hline Primary surgery & 7 \\
\hline Radical surgery & - \\
\hline Secondary surgery & - \\
\hline Platinum-based chemotherapy & 5 \\
\hline Radiotherapy & - \\
\hline
\end{tabular}

compared to controls in the first $24 \mathrm{~h}$ of treatment (i.e., at 0,12 and 24 h; Fig. 1A). However, over time (48-72 h), anisomycin-treated OCSCs showed a significant decrease in cell proliferation compared to the DMSO treated and untreated group (Fig. 1A). After $72 \mathrm{~h}$ of treatment, there was a significant increase in the percentage of cells undergoing early apoptosis (Annexin $\mathrm{V}-\mathrm{FITC}^{+} / \mathrm{PI}^{-}$) in the anisomycin-treated OCSCs compared to the untreated OCSCs (Fig. 1B). Moreover, there were significantly fewer invading anisomycin-treated OCSCs/well (migration cell number, 63 \pm 13 ) than DMSO-treated OCSCs/well $(102 \pm 16)$ or untreated OCSCs/well (115 \pm 15$)$ (Fig. 1C). After $72 \mathrm{~h}$ of treatment, there were substantially fewer colonies in the anisomycin-treated OCSC agar plate $(33.01 \pm 9.17 \%)$ when plated at low density compared to the DMSO-treated OCSC plate $(76.71 \pm 6.26 \%)$ or the untreated OCSC plate $(82.26 \pm 8.32 \%$ ) (Fig. 1D). These results suggest that anisomycin suppresses OCSC proliferation and invasion.

Anisomycin stimulates expression of IncRNA BACE1-AS and apoptosis-related proteins in OCSCs. Our qRT-PCR analysis showed that the expression of 1ncRNA BACE1-AS in the anisomycin-treated OCSCs was significantly elevated compared to the DMSO treated OCSCs or untreated OCSCs after $72 \mathrm{~h}$ (Fig. 2A). In addition, the expression of BACE1, APP, Bcl2 and Bax mRNAs in the anisomycin treated OCSCs was elevated compared to the DMSO treated OCSCs or untreated OCSCs after 72 h (Fig. 2B). Expression of the Ki67 (a cellular marker for proliferation) mRNA in the anisomycin treated OCSCs was decreased compared the DMSO treated or untreated OCSCs (Fig. 2B).

In terms of protein expression, our western blot analysis confirmed that expression of amyloid- $\beta$-related proteins (BACE1 and A $\beta 1-42$ ) were significantly increased in the anisomycin treated OCSCs compared to the DMSO treated or untreated OCSCs after $72 \mathrm{~h}$ (Fig. 3A and B). However, the expression of the Ki67 protein was significantly decreased in the anisomycin treated OCSCs compared the DMSO treated or untreated OCSCs (Fig. 3A and B). Additionally, IF staining confirmed that BACE1 and A $\beta 1-42$ levels increased in the anisomycin treated OCSCs compared the DMSO treated or untreated OCSCs after $72 \mathrm{~h}$ (Fig. 3C). These data indicate that anisomycin induces lncRNA BACE1-AS expression and expression of amyloid- $\beta$-related proteins.

Anisomycin inhibits OCSCs xenograft growth. All mice inoculated with anisomycin or DMSO pretreated OCSCs developed tumors $\sim 7$ weeks after injection. Although both experimental groups eventually developed tumors, tumors formed by anisomycin pretreated OCSCs grew more slowly than those derived from DMSO pretreated OCSCs (Fig. 4A). Furthermore, when mice were sacrificed seven weeks after inoculation with OCSCs, tumors obtained from the anisomycin pretreated group were significantly smaller and lighter than those from the DMSO pretreated group (Fig. 4B and C). Representative hematoxylin and eosin-stained sections of all subcutaneous xenograft tumors were categorized as mixed epithelial ovarian carcinoma of moderate or poor differentiation (grade II/III) (Fig. 4D). Furthermore, immunohistochemical staining indicated that expression of the BACE1 and A $\beta 1-42$ proteins were significantly higher in tumors derived from anisomycin pretreated OCSCs compared to those derived from the DMSO pretreated OCSCs (Fig. 4D). The expression of the Ki67 protein was significantly decreased in the anisomycin pretreated OCSCs compared to the DMSO pretreated OCSCs (Fig. 4D). Thus, xenografts formed by anisomycin pretreated OCSCs were smaller and experienced reduced proliferation compared to those formed by DMSO pretreated OCSCs.

siRNA targeting IncRNA BACE1-AS weakens the effects of anisomycin on OCSC inhibition. To evaluate whether anisomycin regulates proliferation and invasion of OCSCs by inhibiting lncRNA BACE1-AS expression, we used a siRNA targeting BACE1-AS. OCSCs were transfected with either siRNA-BACE1-AS or siRNA-Mock and then treated with anisomycin for $72 \mathrm{~h}$. The MTT assay indicated that the survival ratio of the anisomycin treated siRNA-BACE1-AS transfected OCSCs group was significantly higher than the anisomycin treated siRNA-Mock transfected OCSCs group or the anisomycin treated control group (Fig. 5A). Moreover, western blot analysis showed that BACE1 protein expression was significantly lower in the anisomycin treated siRNA-BACE1-AS 

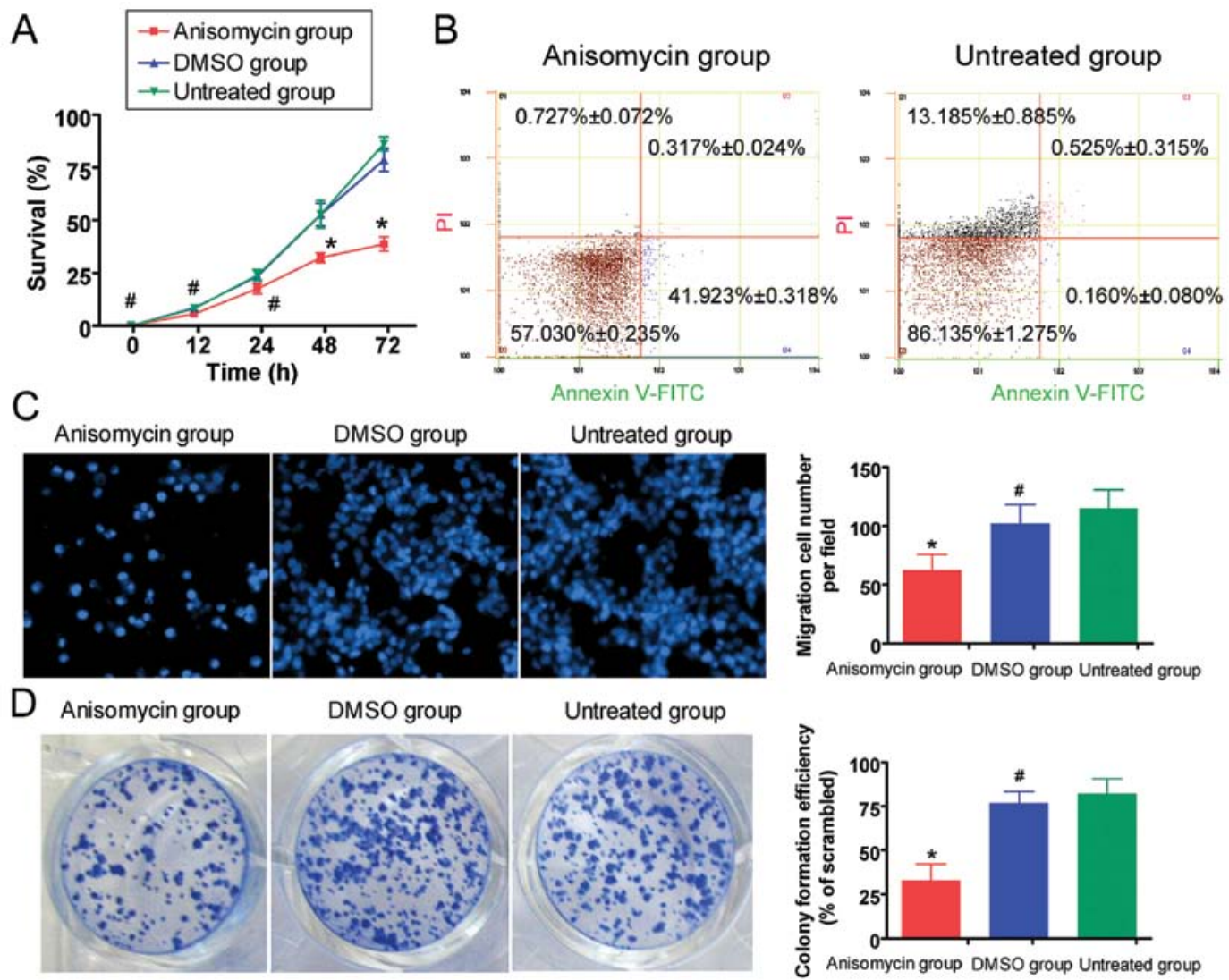

Figure 1. Anisomycin suppresses human OCSC proliferation and invasion. (A) MTT assays showing a significant decrease in proliferation of OCSCs over time when cells are treated with anisomycin; ${ }^{* *} \mathrm{p}<0.01$ vs. untreated group; ${ }^{*} \mathrm{p}<0.05$ vs. untreated group; ${ }^{*} \mathrm{p}>0.05$ vs. untreated group; $\mathrm{n}=3$. (B) Flow cytometric assay showing that the percentage of cells in early apoptosis (Annexin V-FITC ${ }^{+} / \mathrm{PI}$ ) in anisomycin-treated OCSCs is elevated significantly compared to the untreated OCSCs. (C) Transwell migration invasion assay showing significantly fewer invading anisomycin-treated OCSCs/well than DMSO-treated OCSCs/well or untreated OCSCs group/well; * $\mathrm{p}<0.05$ vs. untreated group; ${ }^{*} p>0.05$ vs. untreated group; $n=3$. (D) Soft agar colony formation assay indicating that anisomycin-treated OCSCs create substantially fewer colonies when plated at low density than DMSO-treated OCSCs or untreated OCSCs; ${ }^{*} \mathrm{p}<0.05$ vs. untreated group; $" \mathrm{p}>0.05$ vs. untreated group; $\mathrm{n}=3$.
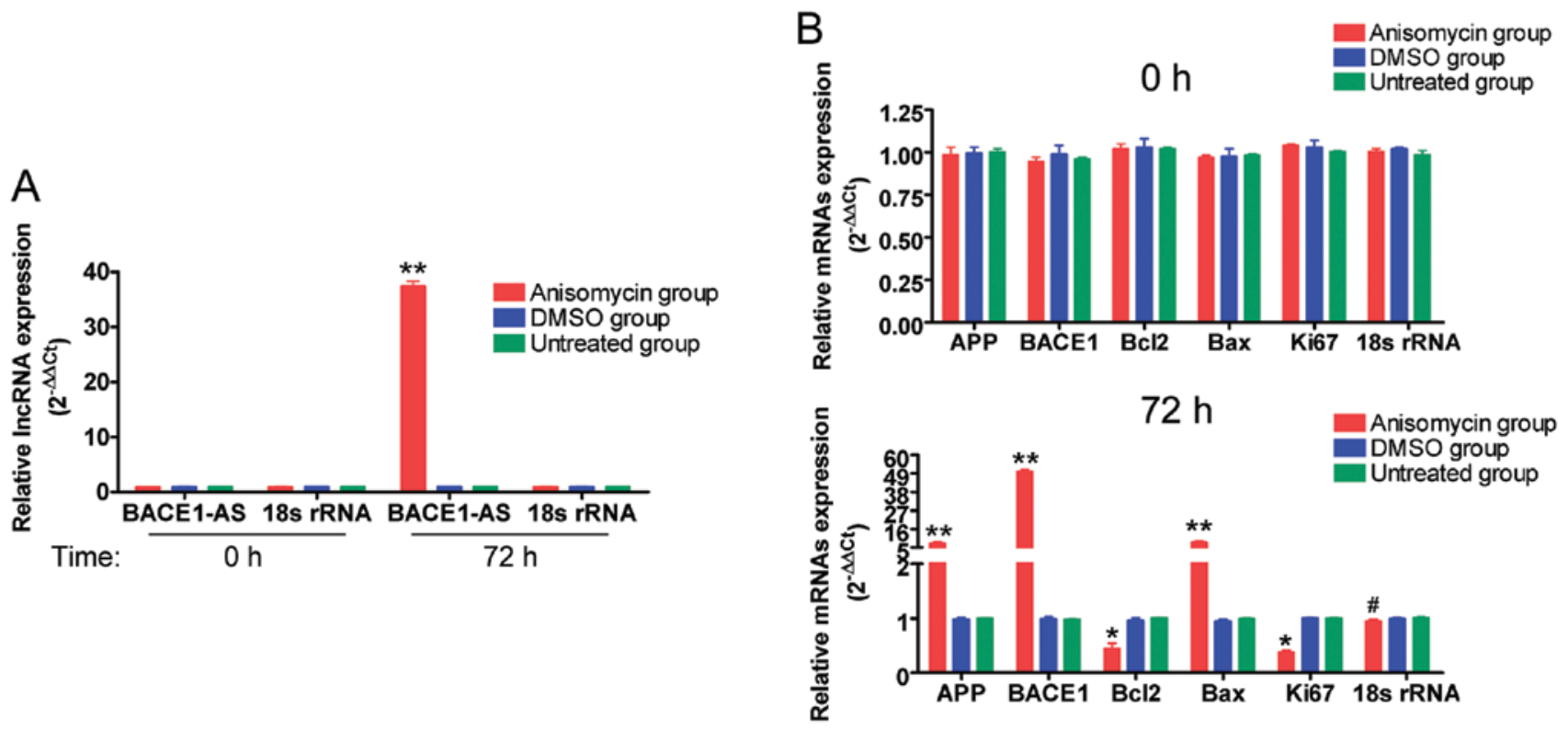

Figure 2. Anisomycin stimulated expression of lncRNA BACE1-AS and apoptosis-related genes in OCSCs. (A) The qRT-PCR assay shows elevated expression of lncRNA BACE1-AS in the anisomycin-treated OCSCs (red) compared to the DMSO treated OCSCs (blue) or untreated OCSCs (green) after $72 \mathrm{~h}$ of treatment; the mRNA levels were calibrated based on levels of $18 \mathrm{~s}$ rRNA; ${ }^{* *} \mathrm{p}<0.01$ vs. untreated group; $\mathrm{n}=3$. (B) The qRT-PCR reveals elevated expression of Bace1, APP, Bcl2 and Bax mRNAs in the anisomycin-treated OCSCs (red) compared to the DMSO treated OCSCs (blue) or the untreated OCSCs (green) after $72 \mathrm{~h}$ of treatment. However, the mRNA expression of Ki67 is decreased in the anisomycin-treated OCSCs compared to the DMSO treated or untreated OCSCs after $72 \mathrm{~h}$ of treatment. The mRNA levels were calibrated based on levels of $18 \mathrm{~s}$ rRNA; *" $\mathrm{p}<0.01$ vs. untreated group; "p $<0.05$ vs. untreated group; ${ }^{\#} \mathrm{p}>0.05$ vs. untreated group; $\mathrm{n}=3$. 
A

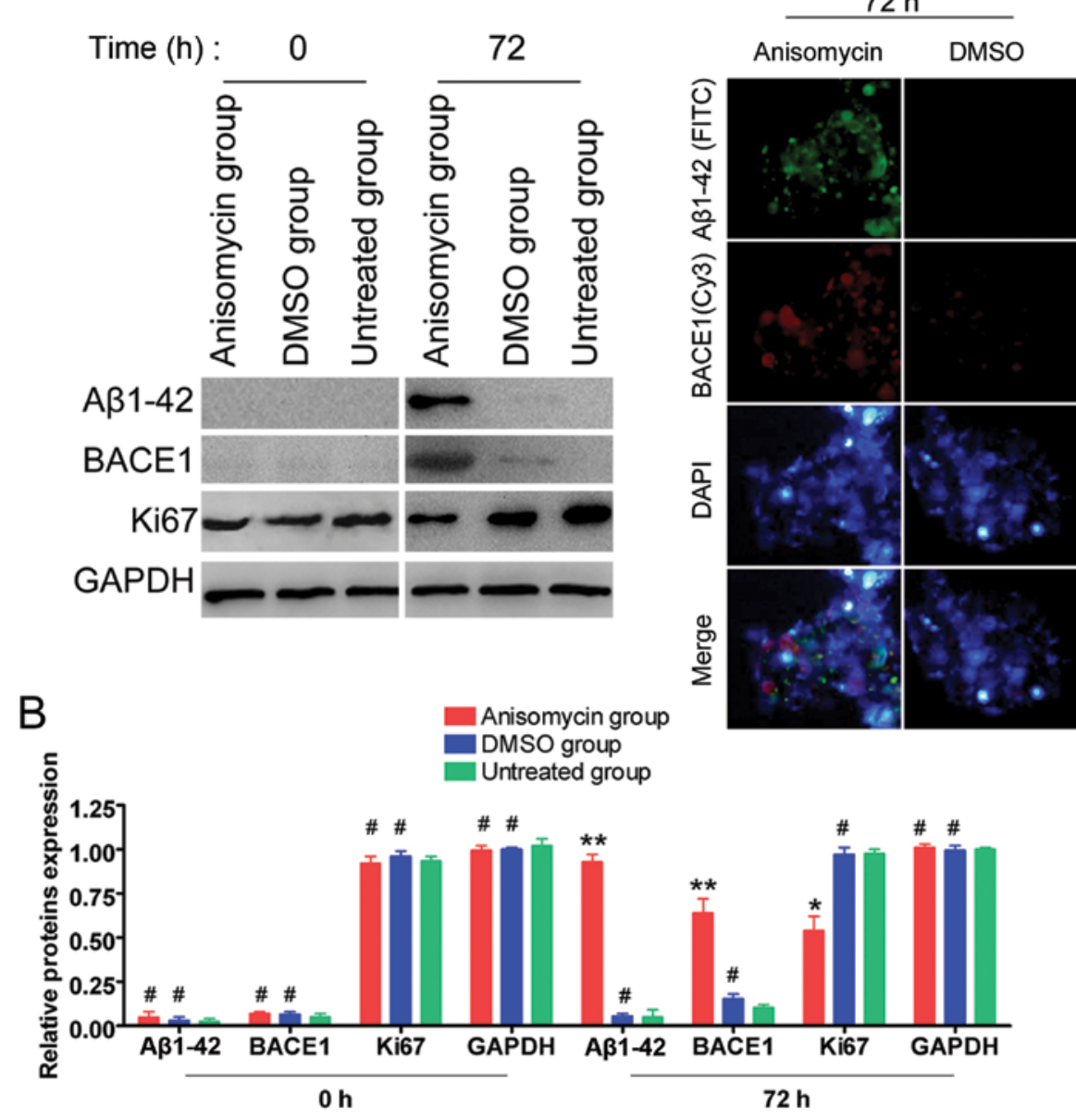

Figure 3. Anisomycin stimulates expression of lncRNA BACE1-AS and apoptosis-proteins in OCSCs. (A and B) Western blotting confirms increased expression of BACE1 and A $31-42$ in anisomycin-treated OCSCs compared to the DMSO OCSCs or the untreated OCSCs after 72 h. However, the expression of Ki67 protein is decreased in anisomycin-treated OCSCs group compared to DMSO-treated or untreated OCSCs. GAPDH was used as a loading control; ${ }^{* *}$ p $<0.01$ vs. untreated group; ${ }^{\#}$ p $>0.05$ vs. untreated group; $n=3$. (C) Immunofluorescence staining confirming increased BACE1 enzyme and A $\beta 1-42$ expression levels in the anisomycin-treated OCSCs compared to DMSO treated or untreated OCSCs after $72 \mathrm{~h}$.

transfected OCSC group compared to the anisomycin treated siRNA-Mock transfected OCSC group or the anisomycin treated control group (Fig. 5B). Finally, northern blot analysis revealed that the hybridization signal of IncRNA BACE1-AS from the anisomycin treated OCSCs after $72 \mathrm{~h}$ was significantly stronger than from the DMSO treated or untreated OCSCs (Fig. 5C); but the hybridization signal of lncRNA BACE1-AS from the anisomycin treated siRNA-BACE1-AS transfected OCSC group was significantly lower than in the anisomycin treated siRNA-Mock transfected OCSC group or the anisomycin treated control group (Fig. 5D). These results indicate that silencing of IncRNA BACE1-AS expression can weaken the effects of anisomycin in OCSCs.

\section{Discussion}

Anisomycin is a small molecule that has previously shown efficacy in inhibiting proliferation of a variety of tumor cells. In the present study, we found anisomycin (at $\mathrm{IC}_{50}$ dose of $8.5 \mu \mathrm{M}$ ) inhibited the proliferation, invasion and tumorigenesis of OCSCs. We found that anisomycin increased the endogenous concentration of A $\beta 1-42$ and expression of BACE1 by elevating lncRNA BACE1-AS expression in OCSCs derived from human ovarian cancer patients.

Similar to our results, previous studies have shown that anisomycin can upregulate APP, BACE1 and PS1 expression by reducing methyltransferase activity in SH-SY5Y cells (11). $\mathrm{Yu}$ et al also showed that anisomycin suppresses Jurkat T cell proliferation by stimulating P53/P21/P27 signaling and arresting cells at the $\mathrm{S}$ or $\mathrm{G} 2 / \mathrm{M}$ phases (17). Anisomycin was shown to enhance apoptosis of renal carcinoma cells by downregulating proteins involved in apoptosis, i.e., Bcl-2, c-FLIP (L) and Mcl-1 (18). Liu et al indicated that anisomycin induces apoptosis of glucocorticoid resistant acute lymphoblastic leukemia cells via activation of phosphorylating mitogenactivated protein kinases p38 and Jun N-terminal kinase (15). Finally, anisomycin was shown to induce glioma cell death by downregulating the protein phosphatase $2 \mathrm{~A}$ catalytic subunit in vitro (19). While our results are similar to previous findings and confirm the antiproliferative and anti-invasive ability of anisomycin, here we identified lncRNA BACE1-AS as a novel mechanism.

We propose that anisomycin increases IncRNA BACE1-AS expression, which in turn, stabilizes BACE1 mRNA and 
A

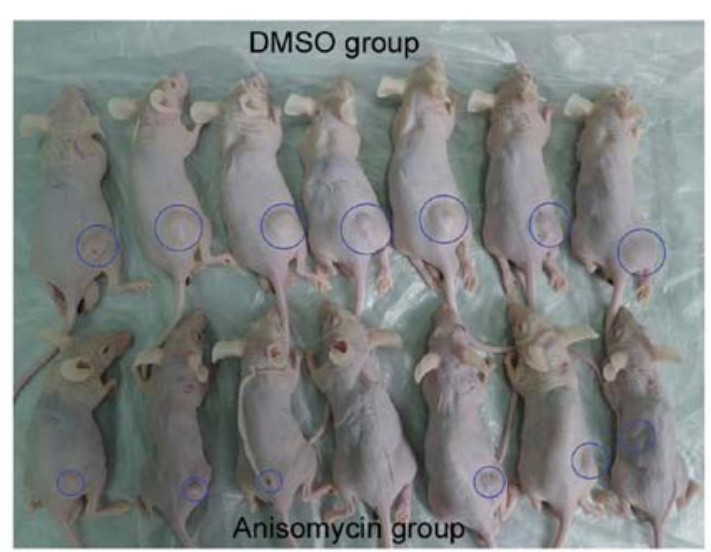

D

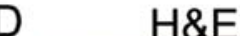

B

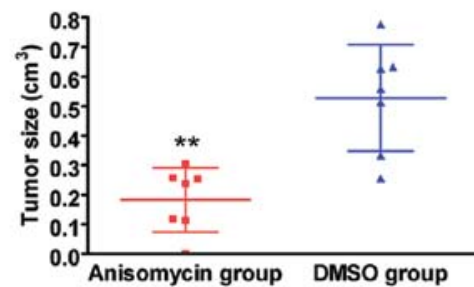

C

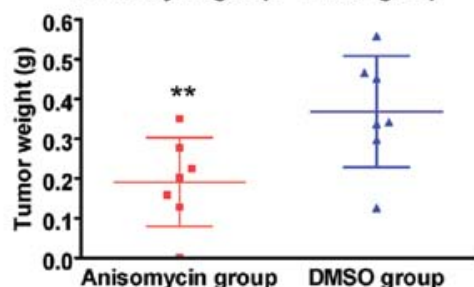

BACE1

Ki67

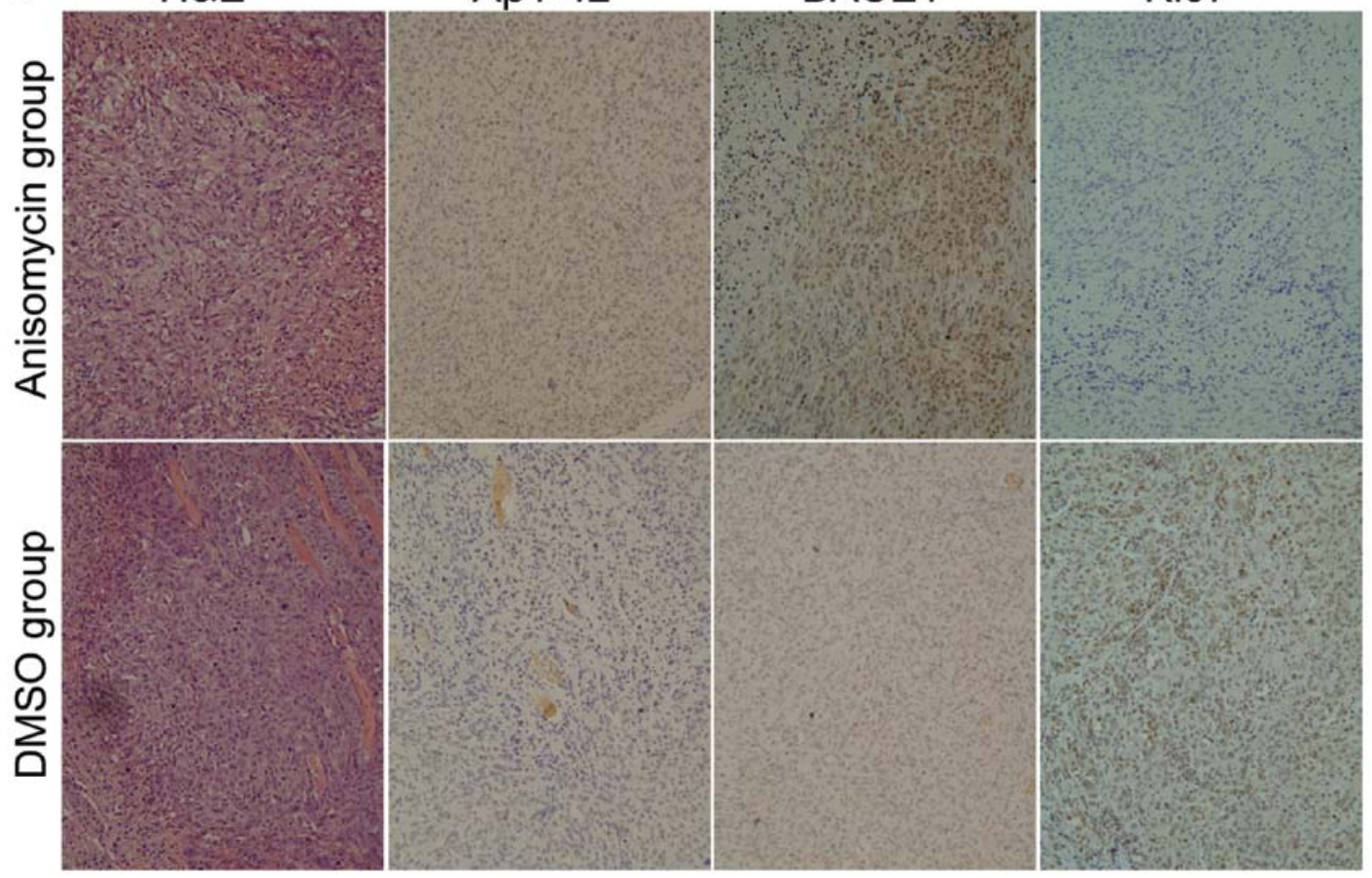

Figure 4. Anisomycin inhibits OCSC xenograft growth. (A) Images of the excised xenograft tumors from the anisomycin pretreated OCSC mice and the DMSO pretreated OCSC mice; blue circle marks the tumor tissue. (B) Tumor size in the anisomycin pretreated OCSC mice (red) and the DMSO pretreated OCSC mice (blue); ${ }^{* *} p<0.01$ vs. DMSO group; $\mathrm{n}=7$. (C) Tumor weight in the anisomycin pretreated OCSC mice (red) and the DMSO pretreated OCSC mice (blue); ${ }^{* *}$ p $<0.01$ vs. DMSO group; $n=7$. (D) Representative hematoxylin and eosin (H\&E) stained sections of all subcutaneous xenograft tumors, which were categorized as mixed epithelial ovarian carcinoma of moderate or poor differentiation (grade II/III). Immunohistochemical staining indicating that BACE1 and A $31-42$ protein expression is significantly higher in tumors derived from anisomycin pretreated OCSCs, compared to tumors from DMSO pretreated OCSCs. The expression of the Ki67 protein is significantly decreased in the tumors derived from anisomycin pretreated OCSCs compared to tumors from DMSO pretreated OCSCs. Original magnification, x200.

increases BACE1 expression through a feed-forward mechanism. As BACE1 is crucial for APP processing and A $\beta 1-42$ production, which are toxic to cells, anisomycin could therefore result in OCSC apoptosis $(11,14,20-25)$. Indeed, our previous studies and others indicate that IncRNA BACE1-AS forms RNA duplexes and increased the stability of BACE1 mRNA, thereby attenuating $A \beta 1-42$ production $(12,13)$. To prove that anisomycin targets IncRNA BACE1-AS, we used siRNA against BACE1-AS and showed that when OCSCs were transfected with siRNA-BACE1-AS and treated with anisomycin, cell toxicity was reduced compared to controls. Thus, silencing of lncRNA BACE1-AS weakens the effects of anisomycin in OCSCs, which confirms that IncRNA BACE1-AS is targeted by anisomycin.
We also found that xenografts formed by anisomycin pretreated OCSCs were smaller and experienced reduced proliferation compared to those formed by DMSO pretreated OCSCs. This suggests that increasing lncRNA BACE1-AS expression (e.g., with anisomycin) is a novel strategy for reducing OCSC proliferation and invasion, and holds potential for future ovarian cancer treatment.

In conclusion, we showed that anisomycin suppresses proliferation and invasion of human OCSCs by increasing lncRNA BACE1-AS levels. In turn, IncRNA BACE1-AS can increase BACE1 mRNA stability, enhance APP processing, and elevate levels of the $A \beta 1-42$ peptide, which are toxic to tumor cells. Therefore, our results suggest a novel mechanism for the antiproliferative or anti-invasive activity of anisomycin, 
A

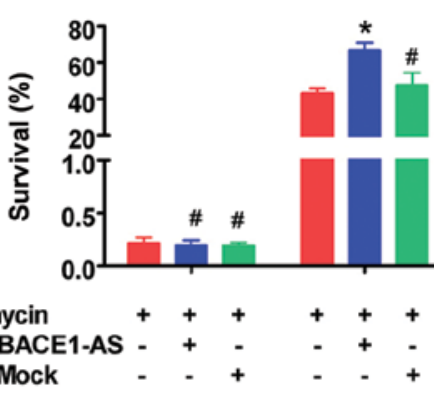

B

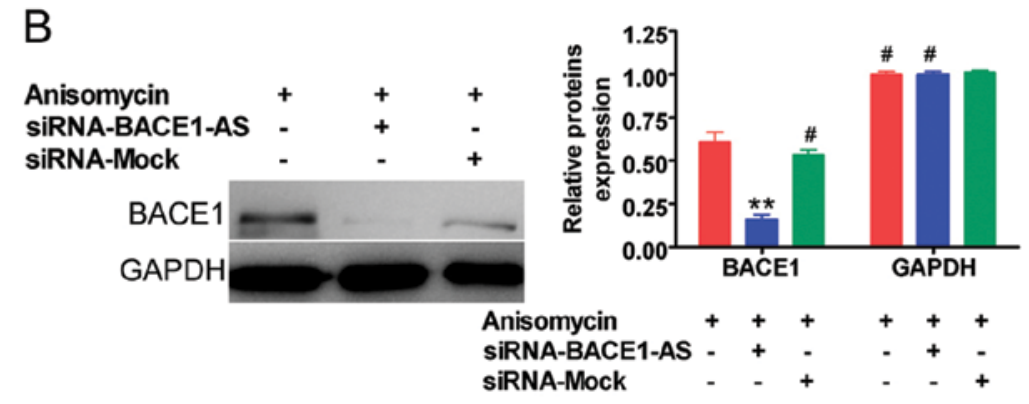

Time (h):

72

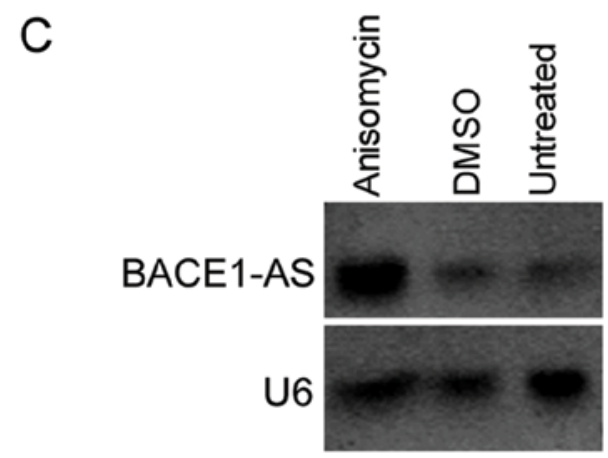

D

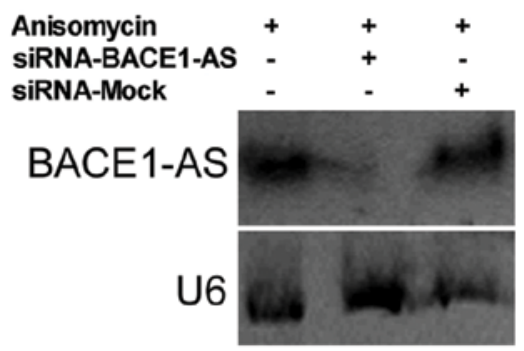

Figure 5. siRNA targeting of lncRNA BACE1-AS weakens the inhibitory effects of anisomycin on OCSCs. (A) The MTT assay indicates that the survival ratio of the anisomycin-treated siRNA-BACE1-AS transfected OCSCs (blue) are significantly higher than the anisomycin-treated siRNA-Mock transfected OCSCs (green) or the anisomycin-treated OCSCs (red) after $72 \mathrm{~h}$; ${ }^{*} \mathrm{p}<0.05$ vs. anisomycin-treated group; ${ }^{*} \mathrm{p}>0.05$ vs. anisomycin-treated group; $\mathrm{n}=3$. (B) Western blot analysis shows that the expression of BACE1 is reduced in the anisomycin-treated siRNA-BACE1-AS transfected OCSCs (blue) compared to the anisomycin-treated siRNA-Mock transfected OCSCs (green) or the anisomycin-treated OCSCs (red) after $72 \mathrm{~h}$. GAPDH was used as a loading control; ${ }^{* *} \mathrm{p}<0.01$ vs. anisomycin-treated group; $" \mathrm{p}>0.05$ vs. anisomycin-treated group; $\mathrm{n}=3$. (C) Northern blot reveals that the hybridization signal of lncRNA BACE1-AS from the anisomycin-treated OCSCs after $72 \mathrm{~h}$ is significantly stronger than from the DMSO treated or untreated OCSCs. (D) The hybridization signal of lncRNA BACE1-AS from the anisomycin-treated siRNA-BACE1-AS transfected OCSCs after $72 \mathrm{~h}$ is significantly weaker than in the anisomycin-treated siRNA-Mock transfected OCSCs or the anisomycin-treated OCSCs; the snRNA U6 was used as a loading control.

and indicate that targeting lncRNA BACE1-AS expression could be a potential treatment for ovarian cancer.

\section{Acknowledgements}

The present study was supported by grant from the National Natural Science Foundation of China (no. 81202811), the Project funded by China Postdoctoral Science Foundation (nos. 2014M550250 and 2015T80455), the Shanghai Municipal Health Bureau Fund (no. 20124320), the Key Discipline Construction Project of Pudong Health Bureau of Shanghai (WZx2014-03), and Discipline Leader Project of Pudong Bureau of Shanghai (PWRd2014-02), and the Shanghai Pudong District Science and Technology Innovation Project (no. PKJ2015-Y52).

\section{References}

1. Cheng W, Liu T, Wan X, Gao Y and Wang H: MicroRNA-199a targets $C D 44$ to suppress the tumorigenicity and multidrug resistance of ovarian cancer-initiating cells. FEBS J 279: 2047-2059, 2012.

2. Høgdall E, Fung ET, Christensen IJ, Yip C, Nedergaard L, Engelholm SA, Risum S, Petri AL, Lundvall L, Lomas L, et al: Proteomic biomarkers for overall and progression-free survival in ovarian cancer patients. Proteomics Clin Appl 4: 940-952, 2010.

3. Liu T, Cheng W, Lai D, Huang Y and Guo L: Characterization of primary ovarian cancer cells in different culture systems. Oncol Rep 23: 1277-1284, 2010.
4. Liu T, Hou L and Huang Y: EZH2-specific microRNA-98 inhibits human ovarian cancer stem cell proliferation via regulating the pRb-E2F pathway. Tumour Biol 35: 7239-7247, 2014.

5. Liu T, Qin W, Hou L and Huang Y: MicroRNA-17 promotes normal ovarian cancer cells to cancer stem cells development via suppression of the LKB1-p53-p21/WAF1 pathway. Tumour Biol 36: 1881-1893, 2015

6. Ma L, Lai D, Liu T, Cheng W and Guo L: Cancer stem-like cells can be isolated with drug selection in human ovarian cancer cell line SKOV3. Acta Biochim Biophys Sin 42: 593-602, 2010.

7. Qin W, Ren Q, Liu T, Huang Y and Wang J: MicroRNA-155 is a novel suppressor of ovarian cancer-initiating cells that targets CLDN1. FEBS Lett 587: 1434-1439, 2013.

8. Yu ZH, Liu T, Zhao YH, Huang YY and Gao YT: Cisplatin targets the stromal cell-derived factor-1-CXC chemokine receptor type 4 axis to suppress metastasis and invasion of ovarian cancer-initiating cells. Tumour Biol 35: 4637-4644, 2014.

9. Zhang S, Balch C, Chan MW, Lai HC, Matei D, Schilder JM, Yan PS, Huang TH and Nephew KP: Identification and characterization of ovarian cancer-initiating cells from primary human tumors. Cancer Res 68: 4311-4320, 2008.

10. Guo X, Wu X, Ren L, Liu G and Li L: Epigenetic mechanisms of amyloid- $\beta$ production in anisomycin-treated SH-SY5Y cells. Neuroscience 194: 272-281, 2011.

11. Fan X, Liu Y, Jiang J, Ma Z, Wu H, Liu T, Liu M, Lixand Tang H: miR-20a promotes proliferation and invasion by targeting APP in human ovarian cancer cells. Acta Biochim Biophys Sin 42: 318-324, 2010.

12. Faghihi MA, Modarresi F, Khalil AM, Wood DE, Sahagan BG, Morgan TE, Finch CE, St Laurent G III, Kenny PJ and Wahlestedt C: Expression of a noncoding RNA is elevated in Alzheimer's disease and drives rapid feed-forward regulation of beta-secretase. Nat Med 14: 723-730, 2008.

13. Liu T, Huang Y, Chen J, Chi H, Yu Z, Wang J and Chen C: Attenuated ability of BACE1 to cleave the amyloid precursor protein via silencing long noncoding RNA BACE1-AS expression. Mol Med Rep 10: 1275-1281, 2014. 
14. Yan $\mathrm{R}$ and Vassar R: Targeting the $\beta$ secretase BACE1 for Alzheimer's disease therapy. Lancet Neurol 13: 319-329, 2014.

15. Liu Y, Ge J, Li Q, Gu L, Guo X, Ma ZG and Zhu YP: Anisomycin induces apoptosis of glucocorticoid resistant acute lymphoblastic leukemia CEM-C1 cells via activation of mitogen-activated protein kinases p38 and JNK. Neoplasma 60: 101-110, 2013.

16. Feng Y, Liu T, Li XQ, Liu Y, Zhu XY, Jankovic J, Pan TH and Wu YC: Neuroprotection by Orexin-A via HIF-1 $\alpha$ induction in a cellular model of Parkinson's disease. Neurosci Lett 579: 35-40, 2014.

17. Yu C, Xing F, Tang Z, Bronner C, Lu X, Di J, Zeng S and Liu J: Anisomycin suppresses Jurkat $\mathrm{T}$ cell growth by the cell cycleregulating proteins. Pharmacol Rep 65: 435-444, 2013.

18. Seo BR, Min KJ, Kim S, Park JW, Park WK, Lee TJ and Kwon TK: Anisomycin treatment enhances TRAIL-mediated apoptosis in renal carcinoma cells through the down-regulation of Bcl-2, c-FLIP(L) and Mcl-1. Biochimie 95: 858-865, 2013.

19. Li JY, Huang JY, Li M, Zhang H, Xing B, Chen G, Wei D, Gu PY and $\mathrm{Hu} \mathrm{WX}$ : Anisomycin induces glioma cell death via downregulation of PP2A catalytic subunit in vitro. Acta Pharmacol Sin 33: 935-940, 2012.

20. Hébert SS, Serneels L, Tolia A, Craessaerts K, Derks C, Filippov MA, Müller U and De Strooper B: Regulated intramembrane proteolysis of amyloid precursor protein and regulation of expression of putative target genes. EMBO Rep 7 : 739-745, 2006
21. Laird FM, Cai H, Savonenko AV, Farah MH, He K, Melnikova T, Wen H, Chiang HC, Xu G, Koliatsos VE, et al: BACE1, a major determinant of selective vulnerability of the brain to amyloidbeta amyloidogenesis, is essential for cognitive, emotional, and synaptic functions. J Neurosci 25: 11693-11709, 2005.

22. Ohno M, Sametsky EA, Younkin LH, Oakley H, Younkin SG, Citron M, Vassar R and Disterhoft JF: BACE1 deficiency rescues memory deficits and cholinergic dysfunction in a mouse model of Alzheimer's disease. Neuron 41: 27-33, 2004.

23. Luo Y, Bolon B, Damore MA, Fitzpatrick D, Liu H, Zhang J, Yan Q, Vassar R and Citron M: BACE1 (beta-secretase) knockout mice do not acquire compensatory gene expression changes or develop neural lesions over time. Neurobiol Dis 14 81-88, 2003.

24. Dominguez D, Tournoy J, Hartmann D, Huth T, Cryns K, Deforce S, Serneels L, Camacho IE, Marjaux E, Craessaerts K, et al: Phenotypic and biochemical analyses of BACE1- and BACE2-deficient mice. J Biol Chem 280: 30797-30806, 2005.

25. Luo Y, Bolon B, Kahn S, Bennett BD, Babu-Khan S, Denis P, Fan W, Kha H, Zhang J, Gong Y, et al: Mice deficient in BACE1, the Alzheimer's beta-secretase, have normal phenotype and abolished beta-amyloid generation. Nat Neurosci 4: 231-232, 2001. 